\title{
THE EFFECT OF A PARALLEL CONDENSER IN THE RECEIVING ANTENNA.*
}

\author{
$\mathrm{By}$ \\ Louis W. Austin. \\ President of the Institute.
}

It is a common practice to make use of a variable condenser in parallel with all or a portion of the inductance of the receiving antenna, for the purpose of increasing the wave length to which the antenna is tuned. This method is very convenient, inasmuch as it does away with the necessity of small inductance steps, and also reduces the total amount of inductance required. It was believed at one time that it was possible in this way to increase the amount of energy delivered to the detector circuit above that obtainable by pure inductive tuning.

The comparison of receiving sets in which the parallel condenser is used, with those using inductive tuning, generally showed that the former were inferior to the latter in efficiency. For this reason an examination was made of the effect of replacing inductance by various amounts of parallel capacity.

The apparatus used consisted of an artificial antenna circuit containing a capacity representing the antenna, the receiving set under test, a resistance of $6 \mathrm{ohms}$ to represent the antenna resistance, and a small coil to which was loosely coupled a buzzer driven wave meter adjusted to the wave length and sending decrement desired. The receiving set, which was originally designed for pure inductive tuning, was provided with a tuned secondary circuit consisting of variable inductance and variable capacity, with the iron pyrites detector connected in parallel to the capacity in the usual way. For the purpose of making quantitative comparisons the telephones were replaced by a sensitive D'Arsonval galvanometer of 2,000 ohms resistance.

The deflection was first measured using pure inductive tuning, the coupling being carefully adjusted to give the maximum 1914.

*Presented before the Institute of Radio Engineers, New York, March 4, 
galvanometer deflection. A variable air condenser was then placed in parallel with the primary of the receiving set, and observations taken on various combinations of inductance and parallel capacity, the coupling between primary and secondary being adjusted in each case to give the maximum possible deflection.

Two such series of observations are shown in Tables I and II. Table I represents an antenna of small capacity, 0.0007 microfarad; while in Table II the antenna is considerably larger, and of 0.002 microfarad capacity. The tables show clearly the decrease in receiving efficiency when inductance is replaced by the parallel condenser. As is to be expected, more capacity can be used in the case of the larger antenna without materially decreasing the intensity of the received signals. In both cases, replacing half of the inductance by capacity reduces the deflection by approximately one third.

A number of other sets of observations were made, in some of which the artificial antenna was excited by sustained oscillations, and in some of which real antennae were used instead of artificial. In all cases, however, the influence of the parallel capacity was substantially the same as in the cases here given.

SUMMARY : Tuning inductances placed in artificial and actual antennae are shunted by a tuning condenser. In all cases the introduction of this capacity is found to reduce the strength of received signals.

TABLE I.

Antenna Capacity $=0.0007$ microfarad

$$
\lambda=2000 \mathrm{~m} . \quad \partial_{1}=0.10
$$

$\begin{array}{rcc}\begin{array}{c}\text { Parallel } \\ \text { Capacity } \\ \text { microfarad }\end{array} & \begin{array}{c}\text { Antenna } \\ \text { Inductance } \\ \text { microhenrys }\end{array} & \begin{array}{c}\text { Deflection } \\ \mathrm{mm} .\end{array} \\ 0 & 1330 & 230 \\ 0.00016 & 1180 & 210 \\ .00032 & 1050 & 195 \\ .00064 & 840 & 180 \\ .00100 & 820 & 160 \\ .00132 & 610 & 140 \\ .00165 & 540 & 125 \\ .00200 & 480 & 105\end{array}$


TABLE II.

$\begin{array}{ccc}\begin{array}{c}\text { Antenna Capacity } \\ \lambda=3000 \mathrm{~m} .\end{array} & 0.002 \text { microfarad } \\ \begin{array}{c}\partial_{1}=0.10 \\ \text { Parallel }\end{array} & \begin{array}{c}\text { Antenna } \\ \text { Inductance } \\ \text { Capacity } \\ \text { microfarad }\end{array} & \begin{array}{c}\text { Deflection } \\ \text { microhenrys }\end{array} \\ 0 & 1100 & 110 \\ 0.00034 & 980 & 105 \\ .00073 & 874 & 95 \\ .00094 & 830 & 92 \\ .00147 & 720 & 90 \\ .00224 & 620 & 74 \\ .00314 & 515 & 56 \\ .00422 & 415 & 42\end{array}$

\section{DISCUSSION.}

John Stone Stone: This paper discusses not only an interesting, but essentially a practical question.

In a very large number of instances the decrement $\grave{\partial}_{1}$, of the wave trains to be received is less than $\delta_{2}$, that of the receiving aerial circuit when tuned by an auxiliary inductance or aerial loading coil to receive them. In such cases, there can be no doubt that the substitution of a condenser in parallel to the primary of the receiving transformer for the auxiliary aerial tuning inductance in series therewith, would diminish the rate of energy reception at the detector in the secondary circuit. In such a case the substitution of the parallel capacity for the series inductance would serve to increase the disparity between the decrement of the wave to be received and the decrement of the receiving aerial circuit. Theoretical considerations and indeed some of my own experiments lead me to the conclusion that, other things being equal, the best condition for receiving a damped train of waves is reached when the decrement of the receiving aerial circuit is equal to the decrement of the received wave trains.

There is another consideration to be kept in mind in drawing deductions from the tests outlined in this paper. When a parallel capacity is substituted for a series inductance, the coupling between the aerial circuit and the detector circuit is automatically altered. To maintain this coupling the same in the 